\section{Combined Heat and Power Systems}

Combined heat and power (CHP) systems generate two forms of energy from a single fuel source by recovering the heat lost in conventional power plants, and using it to generate energy for heating, cooling, dehumidification, and other purposes. A well-designed CHP system can be more than twice as efficient as a traditional fossil fuel plant. Because of its high efficiency, substantial environmental impact, and positive financial return, more and more institutions are turning to this technology to meet their energy goals.

\section{A well-designed CHP system can be more than}

\section{twice as efficient as a traditional fossil fuel plant.}

NREL assists clients in determining if a CHP system is a viable option, then provides support in navigating the process and requirements in deploying the technology at their facility. We provide technical assistance in the following areas:

- Project Development. Clients interested in getting a CHP system up and running often need assistance with project development, including project scheduling, cost estimating (including soft costs), financing mechanisms, and public relations. NREL supports these needs for project development and project management.

- Project Financing. NREL assists its clients in recognizing the most applicable financing pathways and vehicles, as well as financial incentives available for the deployment of a CHP system. Our studies and analyses are designed to develop accurate technical models and provide the information necessary to move to the next steps in the project development process.

- Permitting. Understanding federal, state, and local permitting requirements can be complicated, yet is vital for successful CHP project development. NREL experts are experienced in calculating emissions quantities integral to permit applications, and can also develop lists of required permits with estimated time frames for project scheduling.

\section{CHP Project Support}

NREL provides the following support for CHP projects:

- Project screening to assess initial viability of CHP projects

- Technology assessments, including technical modeling of steam turbines, combustion engines, gas turbines, and all "balance of plant" equipment

- Identification of thermal energy use options, including steam, hot water, and absorption chillers

- Total system modeling using GE's GateCycle software for accurate energy calculation and optimization of the system size and operational scenarios

- Feasibility studies incorporating technical and financial expertise to provide valuable decision-making information

- CHP system application economic evaluations

- Evaluation of peak-shaving scenarios implemented as part of the CHP system

- Technical and managerial assistance for next steps toward implementation.

\section{- Energy Efficiency Optimization. With} General Electric's (GE) GateCycle software, NREL generates accurate energy calculations to better optimize the CHP configuration, resulting in the ideal energy efficiency scenario.

- Microgrid Option Analysis. NREL's microgrid team evaluates the options for integrating a CHP system into an overarching microgrid-based system that can add reliability, energy security, and independence to a facility. Our microgrid technical expertise and project support includes engineering, energy analysis and modeling, financial analysis, and energy management.

- Development and Testing. At NREL's Power Systems Integration Laboratory in the Energy Systems Integration Facility, research focuses on developing and testing large-scale distributedenergy systems for grid-connected, stand-alone, and microgrid applications. The laboratory also offers power testing capabilities, including thermal heating and cooling loops for testing combined heating/cooling and power systems. 


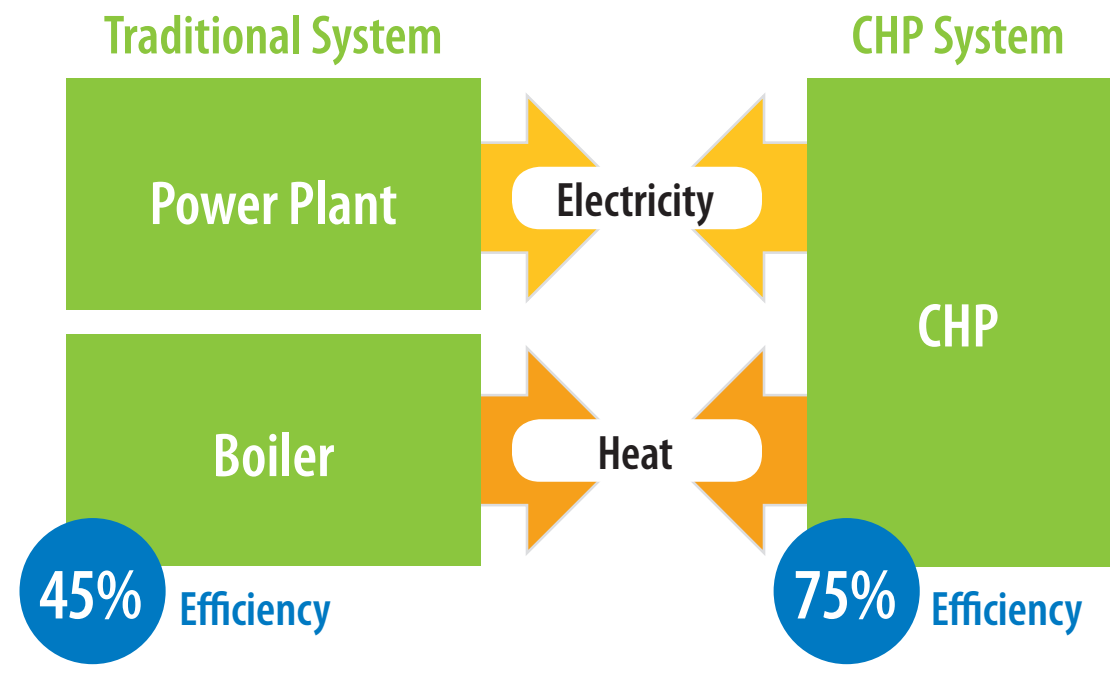

Figure 1. The CHP Process. (Source: U.S. Department fo Energy, Office of Energy Efficiency and Renewable Energy)

\section{CHP Project Examples}

NREL provides project assistance for clients seeking the deployment of CHP technologies, some of which employ novel approaches to project implementation.

- NREL is conducting an evaluation of the technical and economic feasibility of a hybrid power generation facility at the Air Force Academy in Colorado Springs, Colorado. The project includes installing a gas engine to provide peak shaving while capturing the engine's excess heat in the existing heating plant boilers. Routing the exhaust gas from the engine to the hot water boilers decreases the amount of natural gas used in the hot water distribution system, increasing the overall efficiency of the system.

- Through the Army's Energy Initiatives Task Force, NREL is evaluating a potential plant expansion adjacent to the RedStone Arsenal in Huntsville, Alabama. The existing waste-to-energy facility is looking to generate electricity in addition to the large quantity of steam it supplies to RedStone Arsenal through a large steamdistribution loop. Technical and economic analyses are being employed to evaluate various scenarios, and the risks and returns associated with each.
- For the Marine Corps Recruiting Depot at Parris Island, South Carolina, NREL is assessing fuel resources, technology options, and financial implications for multiple CHP scenarios, and assisting with the project development steps necessary to realize project implementation. The Marine Corps Recruiting Depot has an aging fossil fuel steam plant that supplies energy to the facility via a large steam-distribution loop. Large quantities of biomass in the area have incentivized the client to look at biomass CHP generation.

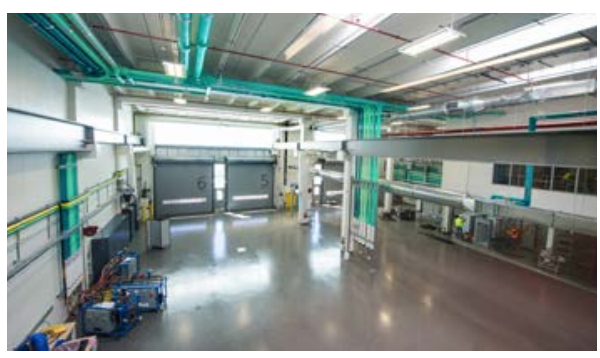

NREL's Power Systems Integration Laboratory in the Energy Systems Integration Facility in Golden, Colorado. Photo by Dennis Schroeder, NREL 24494
NREL's capabilities encompass the laboratory's full range of technologies, which span the energy efficiency and renewable energy spectrum. NREL staff members educate partners on how they can advance sustainable energy applications and also provide clients with best practices for reducing barriers to innovation.

NREL's mission is to be the leader in technology innovation and to advance renewable energy efforts around the world. Let NREL help propel your organization toward a more sustainable energy future.

\section{For more information about NREL's} capabilities, see our website at www.nrel.gov/tech_deployment.

For more information on NREL's CHP system capabilities, contact Gregg Tomberlin at gregg.tomberlin@nrel.gov or 303-275-4643.

\section{National Renewable Energy Laboratory 15013 Denver West Parkway \\ Golden, C0 80401 \\ 303-275-3000 • www.nrel.gov}

NREL is a national laboratory of the U.S. Department of Energy, Office of Energy Efficiency and Renewable Energy, operated by the Alliance for Sustainable Energy, LLC.

NREL/FS-7A30-56775 • July 2013

Front page photography (from the top): iStock 13737597; David Parsons, NREL 06874; iStock 12123595; Dennis Schroeder, NREL 20040 and NREL 19893; Warren Gretz, NREL 10611

Printed with a renewable-source ink on paper containing at least $50 \%$ wastepaper, including $10 \%$ post consumer waste. 